Tohoku J. Exp. Med., 2007, 213, 51-61

\title{
Suprailiac or Abdominal Skinfold Thickness Measured with a Skinfold Caliper as a Predictor of Body Density in Japanese Adults
}

\author{
Shin-IChi Demura ${ }^{1}$ and Susumu Sato ${ }^{2}$ \\ ${ }^{1}$ Kanazawa University, Graduate School of Natural Science and Technology, Ishikawa, Japan \\ ${ }^{2}$ Kanazawa Institute of Technology, Life-Long Sports Core, Ishikawa, Japan
}

Demura, S. and Sato, S. Suprailiac or Abdominal Skinfold Thickness Measured with a Skinfold Caliper as a Predictor of Body Density in Japanese Adults. Tohoku J. Exp. Med., 2007, 213 (1), 51-61 — Measurement of subcutaneous fat thickness with a skinfold caliper is a simple and inexpensive technique for assessment of body composition, but is influenced by the skin site or the obesity level. The resulting measurement errors may influence the prediction accuracy of body density. We therefore aimed to clarify the characteristics of measurement errors with a skinfold caliper and to determine useful measurement sites for the prediction of body density in Japanese adults of wide-ranging age and obesity levels. The present study included 126 Japanese male and 77 female subjects ranging from 21 to 81 years old. They were divided into a "non-obese group" and an "obese group", based on the Japanese criteria of obesity (BMI $\geqq 25 \mathrm{~kg} / \mathrm{m}^{2}$ ). Subcutaneous fat thickness was measured at 14 sites with a skinfold caliper and ultrasound. Percent body fat was measured by dual-energy x-ray absorptiometry, and body density was calculated using Brozek's formula. Sex and obesity level differences in the measurement error of skinfolds (ultrasound minus skinfold caliper measurements) were examined by $2 \times 2$ ANOVA (sex and obesity groups) for each site. The relationship between body density and the systematic error was examined. We developed an accurate prediction equation for body density with smaller measurement and systematic errors. Although measurement errors in skinfold thickness tended to increase with increasing obesity levels, the influence was smaller for the abdominal and suprailiac skinfolds compared with other sites. Measurement of suprailiac or abdominal skinfold thickness is useful to accurately estimate body density in Japanese adults. —— skinfold caliper; measurement error; anthropometry; ultrasound; systematic error

(C) 2007 Tohoku University Medical Press

Measurement of subcutaneous fat thickness with skinfold calipers is a simple and inexpensive technique for body composition assessment that has been used in the field setting (Eston et al. 1994, 2005; Demura et al. 1999; Garcia et al.
2005). In Japan, Nagamine and Suzuki's formula (1964) has been most widely used as an equation for predicting body density. However, it has been reported that estimation accuracy of this equation differed depending on sex and obesity level

Received June 4, 2007; revision accepted for publication July 27, 2007.

Correspondence: Susumu Sato, Kanazawa Institute of Technology, 7-1 Ohgigaoka, Nonoichi, Ishikawa

921-8501, Japan.

e-mail: sssato@neptune.kanazawa-it.ac.jp 
(Nakadomo et al. 1990; Tanaka et al. 1992). This equation was developed in consideration of practicality, and the measurement accuracy of skinfold thickness has not been sufficiently examined. Thus, measurement sites are not always selected based on detailed examinations of measurement error or systematic error in skinfold thickness measurements. In addition, the study sample used for developing this equation was limited to Japanese adolescents with normal physical characteristics.

The skinfold caliper is simple and inexpensive but is susceptible to measurement error (Weits et al. 1986; Forbes et al. 1988). The skinfold caliper assumes a double-layer construction in the subcutaneous adipose tissue, and its measurement accuracy is influenced by tension in the skin. This suggests the possibility that accuracy in skinfold caliper measurements will differ based on the location of the measurement site or the obesity level of the subject. It is therefore important to clarify the influences of the differences in measurement sites and obesity level on the measurement and systematic errors in skinfold measurements. When including obese subjects, a nontraditional site may be judged as a useful site for predicting body density in Japanese adults.

We measured subcutaneous fat thickness at 14 sites throughout the whole body by ultrasound and with a skinfold caliper in Japanese adults with different obesity levels. The error in the skinfold caliper measurements was then calculated in reference to the ultrasound measurement. We also examined the influence of obesity level on the accuracy of the skinfold measurement. This study aimed to clarify the characteristics in measurement error of the skinfold caliper and to determine useful measurement sites for predicting body density in Japanese adults.

\section{MethodS}

\section{Subjects}

Subjects were 126 Japanese males and 77 females aged from 21 to 81 years. They were divided into two obesity groups, the "non-obese group" and the "obese group", based on a criteria of body mass index (BMI) $\geqq$ $25 \mathrm{~kg} / \mathrm{m}^{2}$ which is the criteria for obesity disease in Japan in relation to obesity-related complications (The Examination Committee of Criteria for Obesity Disease in Japan 2002). The sample size and physical characteristics of each sex and obesity group was as follows; 55 non-obese males 71 obese males, 46 non-obese females, and 31 obese females (Table 1).

The study was approved by the Human Subject Ethical Committee of Kanazawa University, and informed consent was provided by each subject prior to participation in this study.

\section{Subcutaneous fat thickness}

In line with previous studies (Komiya et al. 1992, 2000), subcutaneous fat thickness was measured at 14 sites (Fig. 1) with a skinfold caliper (Cambridge Scientific Industries, Inc., Cambridge, MD, USA) and by ultrasound using an EU-2002B (ELK Corp., Osaka). The sites included the right cheek, chin, chest 1 (diagonal fold just superior and lateral to the nipple), chest 2 (vertical fold on the midaxillary line at the level of the xiphoid process), abdomen, suprailiac, triceps, subscapular, back 1 (vertical fold just adjacent to and level with the vertebra prominence), back 2 (vertical fold just adjacent to the spinal column and level with and just below the arcus

TABLE 1. Physical characteristics of study sample.

\begin{tabular}{|c|c|c|c|c|c|}
\hline \multirow{2}{*}{ Variables* } & \multirow{2}{*}{ Units } & \multicolumn{4}{|c|}{ Mean \pm S.D. } \\
\hline & & Non-obese males ${ }^{a}$ & Obese males ${ }^{b}$ & Non-obese females ${ }^{c}$ & Obese females ${ }^{d}$ \\
\hline Age & $\mathrm{yr}$ & $48.1 \pm 15.2$ & $48.2 \pm 11.1$ & $47.3 \pm 15.1$ & $51.0 \pm 10.4$ \\
\hline Height & $\mathrm{cm}$ & $170.6 \pm 5.9$ & $168.9 \pm 5.5$ & $157.0 \pm 6.8$ & $154.1 \pm 5.4$ \\
\hline Weight & $\mathrm{kg}$ & $64.7 \pm 6.9$ & $78.8 \pm 7.5$ & $52.3 \pm 7.0$ & $65.8 \pm 7.5$ \\
\hline BMI & $\mathrm{kg} / \mathrm{m}^{2}$ & $22.2 \pm 1.8$ & $27.6 \pm 1.9$ & $21.2 \pm 2.7$ & $27.7 \pm 2.3$ \\
\hline
\end{tabular}

*BMI, body mass index.

${ }^{\mathrm{a}} n=55,{ }^{\mathrm{b}} n=71,{ }^{\mathrm{c}} n=46,{ }^{\mathrm{d}} n=31$. 

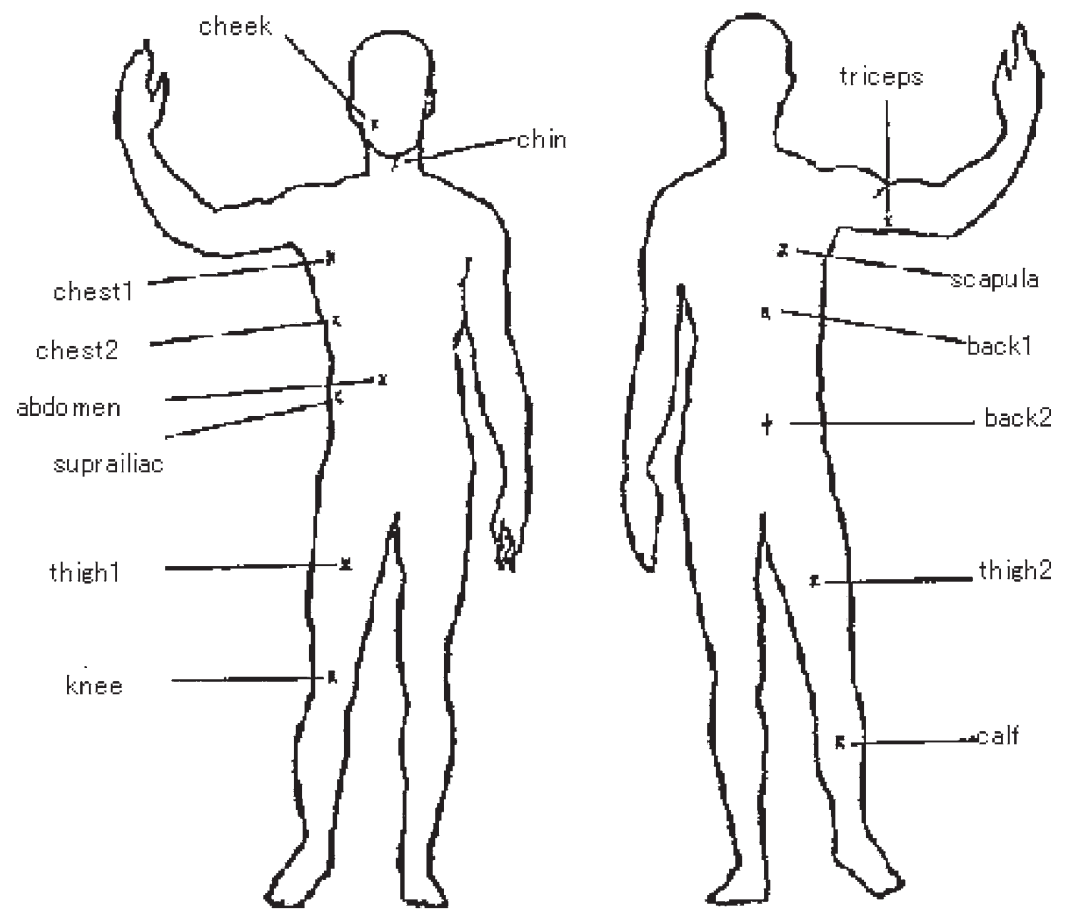

Fig. 1. Measurement sites of subcutaneous fat thickness.

costalis), thigh 1 (vertical fold on the anterior aspect of the thigh midway between the superior aspect of the patella and anterior superior iliac spine), thigh 2 (vertical fold on the posterior aspect of the thigh), knee, and calf (vertical fold on the posterior aspect of the calf at the level of maximum circumference, subject seated with lower leg dangling). A suitably trained tester measured the thickness of each site twice. To confirm intra-tester reliability in ultrasound and skinfold caliper measurements, intra-class correlations were calculated for each site. Intra-class correlation coefficients were higher than 0.95 in the skinfold-caliper method, and higher than 0.89 in the ultrasound method.

\section{Percent body fat and body density}

This study measured percent body fat by Dualenergy x-ray absorptiometry (DEXA) (DPX-L; Lunar Radiation Corp., Madison, WI, USA; whole body scanning, software version 1.3Z). Body density was calculated using Brozek's formula (1963) (body density = $4.57 /[($ percent body fat $[\%] / 100)+4.12])$.

By DEXA, a trained radiology technician measured. DEXA measurements were performed following standard procedures, according to the manufacturer's guidelines, while the subject was lying in a supine position on a table. Whole body scanning time was $20 \mathrm{~min}$, and total $\mathrm{x}$-ray irradiation absorbed by a subject was 5 mrems or lower, which corresponds to $10 \%$ of a standard chest $\mathrm{x}$-ray film.

\section{Measurement error in subcutaneous fat thickness}

To confirm the influence of sex and obesity level on the measurement error of skinfold calipers, sex and obesity-related differences in the measurement error of subcutaneous fat thickness (ultrasound minus skinfold caliper measurements) were examined by $2 \times 2$ analysis of variance (ANOVA) (sex and obesity groups) for each measurement site. Furthermore, to clarify systematic error, correlation coefficients between measurement error and the mean of subcutaneous fat thicknesses determined by both measurement methods were calculated for each site.

Relationship between errors in subcutaneous fat thickness and body density

To clarify the relationship between body density and subcutaneous fat thickness at each site, single regression analyses were conducted using each subcutaneous fat thickness measured by the skinfold caliper as an independent variable and body density as a dependent variable. Then, we calculated the correlation between error in the subcutaneous fat measurement and error in body 
density, which was calculated by body density predicted from the DEXA measurement minus body density predicted from the single regression equation.

\section{Body density prediction}

We attempted to develop a more accurate prediction equation for body density using subcutaneous fat thicknesses, which showed smaller measurement and systematic errors in the above mentioned analyses. Single regression analysis was conducted for each sex and obesity group using subcutaneous fat thickness measured with a skinfold caliper as the independent variable and body density calculated from the DEXA measurement as the dependent variable. To examine systematic error in the predicted body density value, a Bland-Altman plot was created, and the correlation between the error in body density (the reference value minus predicted value in the new equation) and the mean value of the reference and predicted values was calculated. Furthermore, we examined the influence of visceral fat on prediction of body density. This study assumed that waist circumference reflects visceral fat level, and calculated the correlation coefficient between waist circumference and the prediction error in body density (the reference minus predicted values).

\section{RESULTS}

Sex and obesity level differences in error of subcutaneous fat thickness measurements

Table 2 shows the sex and obesity level differences in measurement error (ultrasound minus skinfold caliper) of subcutaneous fat thickness. Significant interactions were found in subcutaneous fat thickness at the chin, subscapular, and calf. A significant obesity level difference was found in all sites except for the abdomen and suprailiac sites, and the measurement error of the skinfold caliper was greater in obesity group than in the normal group. A significant sex difference was found in all sites except for chest 2 (side chest) and back 2 (lower back), and the measurement error was greater in females than in males. Multiple comparisons showed no significant sex difference in the abdomen site. Therefore, these results indicate that the measurement error between the ultrasound and skinfold caliper varies by sex and obesity level and that measurements taken at the abdomen and suprailiac sites are less subject to the influence of differences in obesity level.

Systematic error in subcutaneous fat thickness measured by skinfold caliper

The correlations between the mean value of ultrasound and skinfold caliper measurements and the error (ultrasound minus skinfold caliper) were calculated for each site (Table 3 and Fig. 2). Significant correlations were found in all sites except for the abdominal and suprailiac sites in males of both obesity groups. Significant correlations were found in all sites except for the abdomen in non-obese females and were found in all sites except for the chin, chest 1 , chest 2 , suprailiac, triceps and subscapular in obese females.

\section{Relationship between errors in subcutaneous fat thickness and in body density}

We examined the influence of measurement error in subcutaneous fat thickness on the error in predicting body density. Single regression analysis was conducted for each site using each subcutaneous fat thickness measurement from the skinfold caliper as the independent variable and body density predicted from the DEXA measurement as the dependent variable (Table 4).

The sites with $|r|>0.70$ were chest 1 (0.706), chest $2(0.755)$ in males, and chest $1(0.765)$, chest 2 (0.748), suprailiac (0.714), triceps (0.715), and subscapular (0.744) in females. The sites with $|r|>0.60$ were the abdomen (0.669), back 1 $(0.672)$ and back $2(0.652)$ in males and chin (0.668), calf (0.641), back $1(0.674)$ and back 2 $(0.604)$ in females.

We calculated the error in body density (body density calculated by DEXA measurement minus body density predicted from the regression equation for each site), and examined the relationship between this error in body density and the error in subcutaneous fat thickness measured by the skinfold caliper (Table 4). Although no significant correlations were found in almost all sites in the non-obese groups, significant correlations were found in almost all sites in the obese groups. This trend was also found in both sex groups. In nonobese males, significant correlation was found 
TABLE 2. Sex and obesity level differences in the measurement error (ultrasound minus skinfold caliper) of subcutaneous fat thickness $(\mathrm{mm})$.

\begin{tabular}{|c|c|c|c|c|c|c|c|}
\hline \multirow{2}{*}{\multicolumn{2}{|c|}{ Measurement sites }} & \multicolumn{2}{|c|}{ Mean \pm S.D. ${ }^{a}$} & \multicolumn{3}{|c|}{ Two-way ANOVA ${ }^{b}$} & \multirow{3}{*}{$\begin{array}{c}\begin{array}{c}\text { Multiple } \\
\text { Comparisons }\end{array} \\
\mathrm{M}<\mathrm{d}\end{array}$} \\
\hline & & \multirow{2}{*}{$\begin{array}{l}\text { Non-obesity } \\
-4.01 \pm 2.25\end{array}$} & \multirow{2}{*}{$\begin{array}{c}\text { Obesity } \\
-4.55 \pm 2.21\end{array}$} & \multirow{2}{*}{$\begin{array}{r}\text { Sex } \\
* *\end{array}$} & \multirow{2}{*}{$\frac{\text { Obesity }}{*}$} & \multirow[t]{2}{*}{ Interaction } & \\
\hline Cheek & Males & & & & & & \\
\hline & Females & $-5.92 \pm 3.31$ & $-6.89 \pm 3.49$ & & & & $\mathrm{~N}<\mathrm{O}$ \\
\hline \multirow[t]{2}{*}{ Chin } & Males & $-1.70 \pm 1.98$ & $-2.08 \pm 2.35$ & $* *$ & $* *$ & $*$ & M: ns, F: $N<O$ \\
\hline & Females & $-3.38 \pm 2.99$ & $-5.47 \pm 3.35$ & & & & $\mathrm{~N}, \mathrm{O}: \mathrm{M}<\mathrm{F}$ \\
\hline \multirow[t]{2}{*}{ Chest 1} & Males & $-6.95 \pm 4.24$ & $-9.57 \pm 5.01$ & $* *$ & $* *$ & & $\mathrm{M}<\mathrm{F}$ \\
\hline & Females & $-4.86 \pm 8.96$ & $-5.05 \pm 10.88$ & & & & \\
\hline \multirow[t]{2}{*}{ Chest 2} & Males & $-7.93 \pm 3.95$ & $-11.96 \pm 5.16$ & & $* *$ & & \\
\hline & Females & $-7.69 \pm 6.15$ & $-11.35 \pm 12.80$ & & & & $\mathrm{~N}<\mathrm{O}$ \\
\hline \multirow[t]{2}{*}{ Back 1} & Males & $-8.71 \pm 3.29$ & $-13.20 \pm 3.98$ & & $* *$ & & \\
\hline & Females & $-8.85 \pm 6.03$ & $-14.67 \pm 9.15$ & & & & $\mathrm{~N}<\mathrm{O}$ \\
\hline \multirow[t]{2}{*}{ Back 2} & Males & $-6.79 \pm 3.13$ & $-10.65 \pm 4.11$ & $* *$ & $* *$ & & $\mathrm{M}<\mathrm{F}$ \\
\hline & Females & $-10.62 \pm 5.26$ & $-15.72 \pm 6.73$ & & & & $\mathrm{~N}<\mathrm{O}$ \\
\hline \multirow[t]{2}{*}{ Triceps } & Males & $-4.40 \pm 2.54$ & $-5.86 \pm 3.57$ & $* *$ & $* *$ & & $\mathrm{M}<\mathrm{F}$ \\
\hline & Females & $-9.74 \pm 5.02$ & $-10.55 \pm 6.42$ & & & & \\
\hline \multirow[t]{2}{*}{ Subscapular } & Males & $-9.71 \pm 4.15$ & $-12.85 \pm 4.87$ & $* *$ & $* *$ & $*$ & $\mathrm{M}, \mathrm{F}: \mathrm{N}<\mathrm{O}$ \\
\hline & Females & $-9.53 \pm 6.74$ & $-16.22 \pm 8.70$ & & & & $\mathrm{~N}: \mathrm{ns}, \mathrm{O}: \mathrm{M}<\mathrm{F}$ \\
\hline \multirow[t]{2}{*}{ Abdomen } & Males & $-6.96 \pm 6.74$ & $-6.86 \pm 8.37$ & $*$ & & & \\
\hline & Females & $-9.28 \pm 8.32$ & $-8.53 \pm 11.25$ & & & & \\
\hline \multirow[t]{2}{*}{ Suprailiac } & Males & $-4.50 \pm 5.31$ & $-5.20 \pm 6.65$ & $* *$ & & & $\mathrm{M}<\mathrm{F}$ \\
\hline & Females & $-7.75 \pm 7.92$ & $-9.75 \pm 9.83$ & & & & \\
\hline \multirow[t]{2}{*}{ Thigh 1} & Males & $-6.49 \pm 6.11$ & $-8.58 \pm 3.60$ & ** & $* *$ & & $\mathrm{M}<\mathrm{F}$ \\
\hline & Females & $-12.97 \pm 6.48$ & $-15.28 \pm 6.08$ & & & & $\mathrm{~N}<\mathrm{O}$ \\
\hline \multirow[t]{2}{*}{ Thigh 2} & Males & $-6.64 \pm 5.55$ & $-8.74 \pm 4.62$ & $* *$ & $* *$ & & $\mathrm{M}<\mathrm{F}$ \\
\hline & Females & $-10.08 \pm 6.71$ & $-12.38 \pm 8.48$ & & & & \\
\hline \multirow[t]{2}{*}{ Knee } & Males & $-4.36 \pm 5.82$ & $-5.93 \pm 3.25$ & $* *$ & $* *$ & & $\mathrm{M}<\mathrm{F}$ \\
\hline & Females & $-8.88 \pm 5.62$ & $-10.84 \pm 8.31$ & & & & $\mathrm{~N}<\mathrm{O}$ \\
\hline \multirow[t]{2}{*}{ Calf } & Males & $-4.05 \pm 3.64$ & $-5.35 \pm 3.43$ & $* *$ & $* *$ & $*$ & M: ns, F: $N<O$ \\
\hline & Females & $-7.97 \pm 5.42$ & $-12.45 \pm 6.02$ & & & & $\mathrm{~N}, \mathrm{O}: \mathrm{M}<\mathrm{F}$ \\
\hline
\end{tabular}

This table shows the sex and obesity level differences in measurement error (ultrasound minus skinfold caliper) of subcutaneous fat thickness $(\mathrm{mm})$ for each measurement site. ${ }^{\text {a }}$ The unit of numerical values (mean \pm S.D.) in this Table is mm. ${ }^{b *} p<0.05,{ }^{* *} p<0.01 .{ }^{\mathrm{c}} \mathrm{M}$, males; $\mathrm{F}$, females; $\mathrm{N}$, non-obesity; O, obesity; ns, not significant. ${ }^{\mathrm{d}}$ Magnitude relation based on absolute value in the measurement error is shown. 
TABLE 3. Systematic error ${ }^{a}$ for each site.

\begin{tabular}{|c|c|c|c|c|c|c|}
\hline & \multicolumn{3}{|c|}{ Males } & \multicolumn{3}{|c|}{ Females } \\
\hline & Non-obesity & Obesity & Total & Non-obesity & Obesity & Total \\
\hline Cheek & $-0.88 * *$ & $-0.55 * *$ & $-0.71 * *$ & $-0.60 * *$ & $-0.38 *$ & $-0.56^{* *}$ \\
\hline Chin & $-0.68 * *$ & $-0.32 *$ & $-0.47 * *$ & $-0.63 * *$ & $-0.15 \mathrm{~ns}$ & $-0.50 * *$ \\
\hline Chest 1 & $-0.70 * *$ & $-0.54 * *$ & $-0.64^{* *}$ & $-0.75 * *$ & $-0.29 \mathrm{~ns}$ & $-0.57 * *$ \\
\hline Chest 2 & $-0.63 * *$ & $-0.50 * *$ & $-0.64 * *$ & $-0.58 * *$ & $-0.24 \mathrm{~ns}$ & $-0.55^{* *}$ \\
\hline Back 1 & $-0.62 * *$ & $-0.50 * *$ & $-0.69^{* *}$ & $-0.72 * *$ & $-0.36^{*}$ & $-0.64 * *$ \\
\hline Back 2 & $-0.60 * *$ & $-0.58 * *$ & $-0.68 * *$ & $-0.56^{* *}$ & $-0.42 *$ & $-0.61 * *$ \\
\hline Triceps & $-0.60 * *$ & $-0.67 * *$ & $-0.66^{* *}$ & $-0.69 * *$ & $0.24 \mathrm{~ns}$ & $-0.33^{*}$ \\
\hline Subscapular & $-0.62 * *$ & $-0.66 * *$ & $-0.69 * *$ & $-0.73 * *$ & $-0.20 \mathrm{~ns}$ & $-0.69 * *$ \\
\hline Abdomen & $0.20 \mathrm{~ns}$ & $-0.02 \mathrm{~ns}$ & $0.07 \mathrm{~ns}$ & $-0.15 \mathrm{~ns}$ & $0.58 * *$ & $0.16 \mathrm{~ns}$ \\
\hline Suprailiac & $-0.13 \mathrm{~ns}$ & $-0.17 \mathrm{~ns}$ & $-0.15 n s$ & $-0.48^{*}$ & $0.28 \mathrm{~ns}$ & $-0.24 n s$ \\
\hline Thigh 1 & $-0.76^{* *}$ & $-0.80 * *$ & $-0.78 * *$ & $-0.85 * *$ & $-0.59 * *$ & $-0.76 * *$ \\
\hline Thigh 2 & $-0.70 * *$ & $-0.70 * *$ & $-0.71 * *$ & $-0.74 * *$ & $-0.72 * *$ & $-0.74 * *$ \\
\hline Knee & $-0.79 * *$ & $-0.44 * *$ & $-0.61^{* *}$ & $-0.75^{* *}$ & $-0.50 * *$ & $-0.63 * *$ \\
\hline Calf & $-0.74 * *$ & $-0.83 * *$ & $-0.79^{* *}$ & $-0.77 * *$ & $-0.47 * *$ & $-0.70 * *$ \\
\hline
\end{tabular}

This table shows the result of examining systematic error for each measurement site. The values in the Table show the correlations between the mean value of ultrasound and skinfold caliper measurements and the error (ultrasound minus skinfold caliper).

a The values in this Table mean the correlations between the mean value of ultrasound and skinfold caliper measurements and the error (ultrasound minus skinfold caliper). ${ }^{*} * p<0.01,{ }^{*} p<0.05$, ns, not significant.

only for the abdomen. In obese females, significant correlations were found at all sites except for the abdomen and suprailiac sites.

\section{Proposal of prediction equation for body den- sity}

We attempted to develop a prediction equation for body density using subcutaneous fat thickness at the abdominal and suprailiac sites, which both showed smaller measurement and systematic errors. Single regression analysis was conducted for each sex and obesity group using the body density calculated from the DEXA measurements as the dependent value and the sum of the subcutaneous fat thicknesses at both sites as the independent variable. Furthermore, single regression analysis was similarly conducted using the sum of the subcutaneous fat thicknesses at the sites used in Nagamine and Suzuki's equation (triceps and subscapular) as the independent variable. Prediction equations obtained from the regression analyses are shown in Table 5. The $R^{2}$ (coefficient of determination) and standard error of estimation (SEE) values in the equation using the abdominal and suprailiac sites were almost equal to those in the equation using the triceps and subscapular sites. The accuracy of body density calculated from the subcutaneous fat thickness tended to be higher in females than in males.

Furthermore, to confirm systematic error in both equations, a Bland-Altman plot was created, and the correlation between the error in the body density values predicted from two equations and the mean value of these predicted values was calculated. Although significant systematic error in body density was not found when predicting from subcutaneous fat thicknesses at the abdominal and suprailiac sites, it was found $(r=0.474, p<0.05)$ when predicting from sites at the triceps and subscapular sites (Table 5 and Fig. 3).

To examine the influence of visceral fat on body density prediction, the correlation coeffi- 

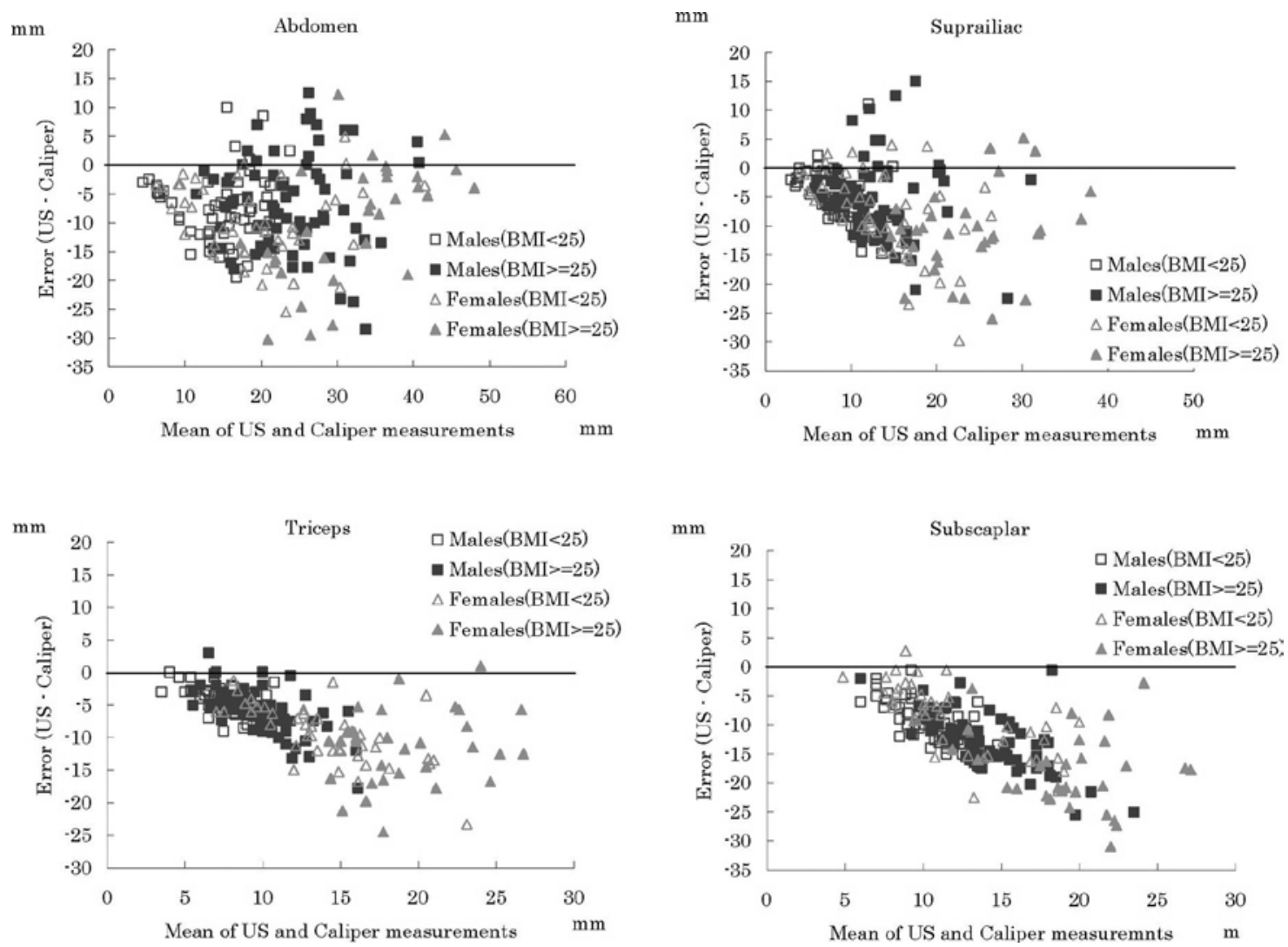

Fig. 2. Systematic error in skinfold thickness. This figure shows systematic error in skinfold thickness at abdomen, suprailiac, triceps and subscapular.

cients between waist circumference and the error in the predicted body density were calculated with the above mentioned equations. In the equation using subcutaneous fat thickness at abdominal and suprailiac sites, a significant correlation was found only in the non-obese male group $(r=-0.32$, $p<0.05)$. In the equation using subcutaneous fat thickness at the triceps and subscapular skinfolds, significant correlations were found in non-obese male and female groups (non-obese males: $r=$ $-0.52, p<0.05$; non-obese females: $r=-0.34$, $p<0.05)$.

\section{Discussion}

Subcutaneous fat thickness has been widely used as a simple body composition assessment method to determine body fat distribution or body density. Nagamine and Suzuki's formula (1964), which has been the most widely used in Japan, predicts body density from triceps and subscapu- lar skinfolds. There are two common methods of subcutaneous fat thickness measurement: ultrasound and skinfold calipers. The latter method is very simple but has the problem of measurement error (Weits et al. 1986; Forbes et al. 1988). However, there are a few reports examining the influence of sex and obesity level on the error of skinfold caliper measurements for the Japanese with wide-ranging obesity levels (Nakadomo et al. 1990; Tanaka et al. 1992). When Nagamine and Suzuki's formula (1964) was developed, subjects were selected from a limited range of age and obesity levels. To determine which measurement site is the most suitable for predicting body density, we examined the characteristics of the error of skinfold measurement at 14 sites throughout the whole body.

As shown in the Fig. 2, measurement error for skinfold calipers increases with an increase in subcutaneous fat thickness. Sites without this 
TABLE 4. Correlations ${ }^{\dagger}$ between skinfold thickness and body density, and between the error in body density and the measurement error in skinfold thickness.

\begin{tabular}{|c|c|c|c|c|c|c|c|c|c|}
\hline & \multicolumn{3}{|c|}{$\begin{array}{l}\text { Correlation between skinfold } \\
\text { thickness and body density }\end{array}$} & \multicolumn{6}{|c|}{$\begin{array}{l}\text { Correlation between the prediction error in body density } \\
\text { and measurement error in skinfold thickness }\end{array}$} \\
\hline & \multirow{2}{*}{ Males $^{a}$} & \multirow{2}{*}{ Females $^{\text {b }}$} & \multirow{2}{*}{ Total } & \multicolumn{3}{|c|}{ Males $^{a}$} & \multicolumn{3}{|c|}{ Females $^{\mathrm{b}}$} \\
\hline & & & & Non-obesity ${ }^{\mathrm{c}}$ & Obesity $^{\mathrm{d}}$ & Total & Non-obesity ${ }^{\mathrm{e}}$ & Obesity $^{\mathrm{f}}$ & Total \\
\hline Cheek & $-0.44 * *$ & $-0.56 * *$ & $-0.62 * *$ & -0.07 & $-0.49 * *$ & -0.14 & -0.12 & $-0.55^{* *}$ & -0.11 \\
\hline Chin & $-0.39 * *$ & $-0.67 * *$ & $-0.64 * *$ & -0.05 & $-0.48 * *$ & -0.16 & -0.07 & $-0.55^{* *}$ & -0.16 \\
\hline Chest 1 & $-0.71 * *$ & $-0.49 * *$ & $-0.49 * *$ & 0.05 & $-0.58 * *$ & -0.14 & -0.22 & $-0.57 * *$ & $-0.25^{*}$ \\
\hline Chest 2 & $-0.76^{* *}$ & $-0.75^{* *}$ & $-0.72 * *$ & 0.15 & $-0.61 * *$ & -0.15 & 0.09 & $-0.45^{*}$ & -0.10 \\
\hline Back 1 & $-0.67 * *$ & $-0.67 * *$ & $-0.63^{* *}$ & 0.15 & $-0.42 * *$ & 0.00 & 0.02 & $-0.48^{* *}$ & -0.11 \\
\hline Back 2 & $-0.65 * *$ & $-0.60 * *$ & $-0.69 * *$ & -0.11 & $-0.45^{* *}$ & -0.08 & -0.17 & $-0.52 * *$ & -0.13 \\
\hline Triceps & $-0.50 * *$ & $-0.71 * *$ & $-0.73^{* *}$ & -0.23 & $-0.48 * *$ & -0.17 & -0.16 & $-0.51 * *$ & -0.22 \\
\hline Subscapular & $-0.59 * *$ & $-0.74 * *$ & $-0.65^{* *}$ & 0.07 & $-0.59 * *$ & -0.10 & -0.19 & $-0.36^{*}$ & -0.15 \\
\hline Abdomen & $-0.67 * *$ & $-0.76^{* *}$ & $-0.74 * *$ & $-0.26^{*}$ & $-0.47 * *$ & $-0.36^{*}$ & 0.00 & -0.03 & -0.02 \\
\hline Suprailiac & $-0.58 * *$ & $-0.71 * *$ & $-0.73^{* *}$ & -0.24 & $-0.41 * *$ & $-0.26^{*}$ & -0.12 & -0.22 & -0.12 \\
\hline Thigh 1 & $-0.51 * *$ & $-0.56^{* *}$ & $-0.68 * *$ & -0.19 & $-0.32 * *$ & -0.10 & -0.27 & $-0.42^{*}$ & -0.15 \\
\hline Thigh 2 & $-0.45^{* *}$ & $-0.44 * *$ & $-0.57 * *$ & -0.15 & $-0.41 * *$ & -0.09 & -0.24 & $-0.45^{*}$ & -0.14 \\
\hline Knee & $-0.38 * *$ & $-0.48 * *$ & $-0.59 * *$ & -0.18 & $-0.37 * *$ & -0.13 & -0.20 & $-0.53 * *$ & -0.17 \\
\hline Calf & $-0.40 * *$ & $-0.64 * *$ & $-0.66 * *$ & -0.12 & $-0.35^{* *}$ & -0.07 & -0.20 & $-0.52 * *$ & -0.11 \\
\hline
\end{tabular}

This table shows the correlations between body density and skinfold for each site and the correlations between the predicted error in body density and the measurement error in skinfold caliper for each site.

$\dagger * * p<0.01, * p<0.05$

${ }^{\mathrm{a}} n=126,{ }^{\mathrm{b}} n=77,{ }^{\mathrm{c}} n=55,{ }^{\mathrm{d}} n=71,{ }^{\mathrm{e}} n=46,{ }^{\mathrm{f}} n=31$.
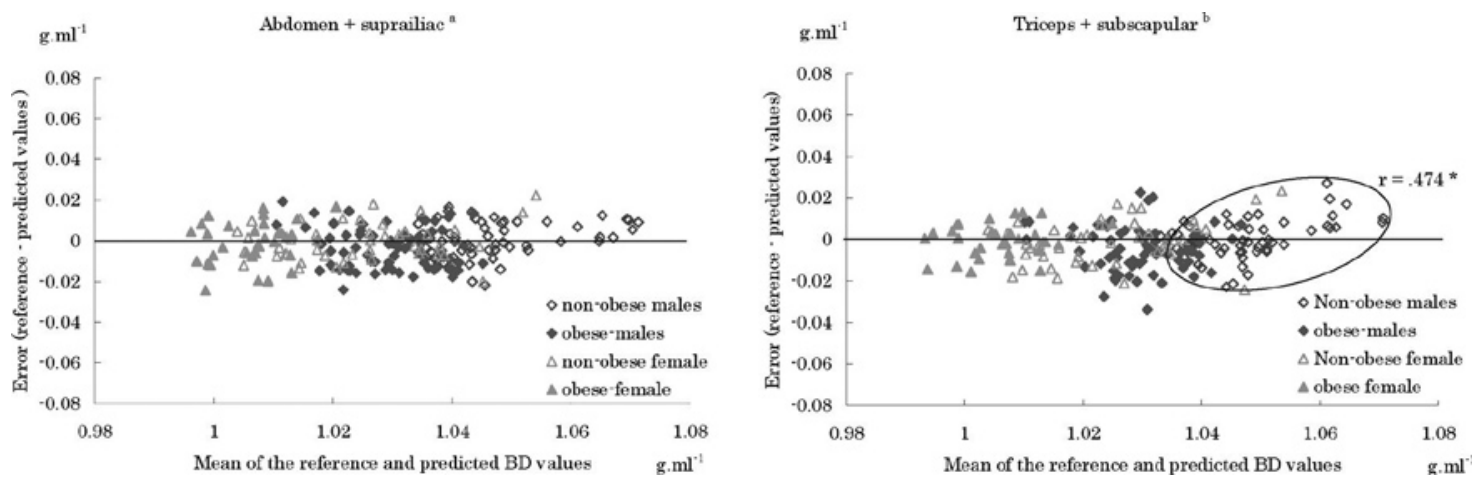

Fig. 3. Comparison of the accuracy of the prediction equations for body density (Bland-Altman plots). This figure shows the result of comparing the accuracy of the prediction equations for body density. The result of regression analysis of these equations is shown in Table 5.

${ }^{a}$ The systematic error of the regression equation using the sum of skinfolds (abdomen + suprailiac) as independent value and using body density calculating from DEXA measurement as dependent variable.

${ }^{\mathrm{b}}$ The systematic error of the regression equation using the sum of skinfolds (triceps + subscapular) as independent value and using body density calculating from DEXA measurement as dependent variable. 


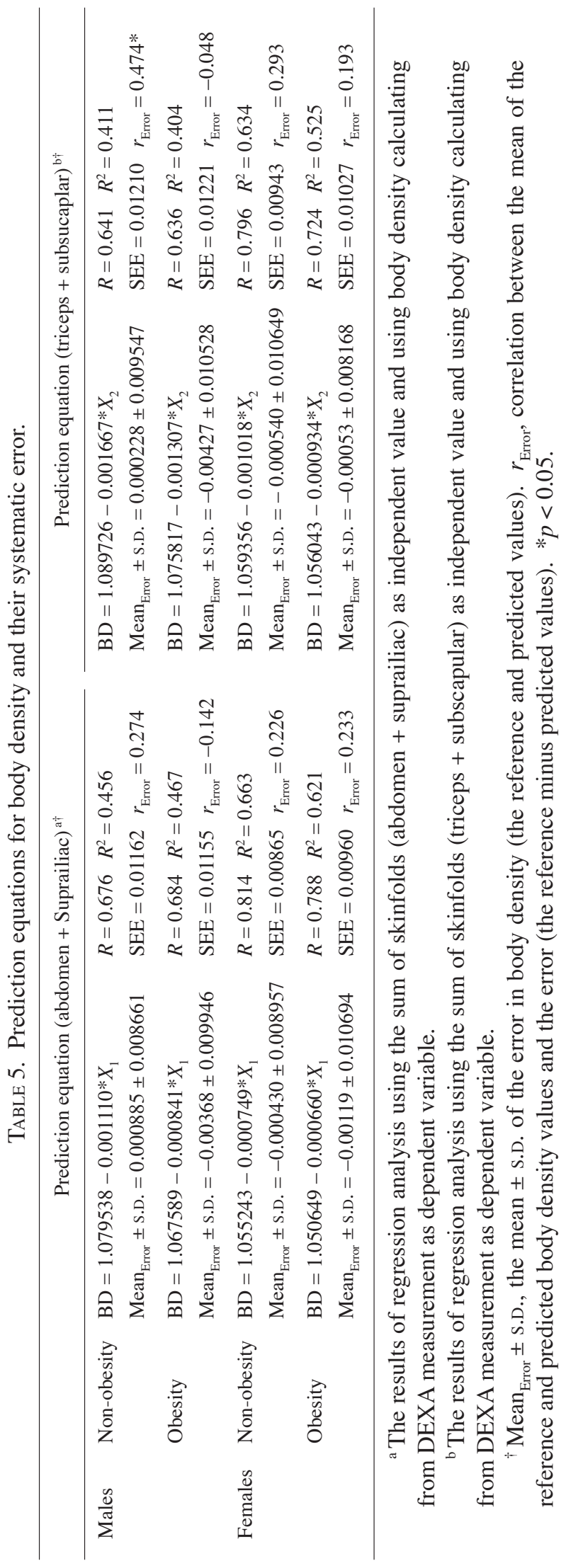

trend were the abdomen and suprailiac. For these sites, there was no significant obesity level difference in the error of the subcutaneous fat thickness measurement, and these sites may consequently be impervious to the influence of differences in obesity levels. In the case of the triceps and subscapular, which are used in Nagamine and Suzuki's formula (1964), significant systematic error was found in both the male groups but not in the obese female group. Furthermore, there was significant interaction in the skinfold measurement error at the subscapular, and the tendency for skinfold measurement error at this site varied by sex and obesity level. Thus, by using skinfold measurements at the abdomen and suprailiac sites, we may be able to predict body density without systematic error.

We developed an equation predicting body density from subscapular and abdominal skinfolds, and compared the prediction accuracy and systematic error of our equation with the equation using established sites (triceps and subscapular). The determination coefficient was almost equal between these equations irrespective of sex or obesity level. Systematic error was significant for non-obese males, when using skinfolds at the triceps and subscapular. The SEE in males tended to be smaller when using suprailiac and abdominal skinfolds and that for females did when using triceps and subscapular skinfolds. These results suggest that body density can be accurately estimated from the suprailiac and abdominal subcutaneous fat thicknesses, comparable to the existing equation, and that it is preferable to estimate body density in males using suprailiac and abdominal subcutaneous fat. Furthermore, body density in females can be equally well estimated by both methods, although the estimation error was a little smaller when using the triceps and subscapular skinfolds.

Systematic error in suprailiac and abdominal skinfolds tended to be greater in females than in males, but the systematic error in body density estimation showed an inverse trend. Thus, the systematic error in skinfold caliper measurements was not directly reflected in the systematic error in body density estimation. However, the rela- 
tionships between error in subcutaneous fat thickness measurements and those in estimated body density values were almost significant in almost all sites for obese male and female groups. This suggests that the increase in measurement error in subcutaneous fat thickness significantly relates to the estimation error of body density. Therefore, to estimate body density, it is more preferable to use subcutaneous fat thickness estimations from sites that are less prone to produce error in skinfold measurements. Although our equation for body density, which uses suprailiac and abdominal skinfolds, has an estimation accuracy comparable to the existing method, which uses triceps and subscapular skinfolds, our method may be more useful with respect to estimation error and systematic error.

Furthermore, we examined the influence of visceral fat on the prediction accuracy of body density by these equations. In the equation using suprailiac and abdominal skinfolds, a significant correlation between waist circumference and prediction error in body density was found only in the non-obese male group, and in the equation using triceps and subscapular skinfolds, significant correlations were found in non-obese male and female groups. These results indicate that when predicting body density from subcutaneous fat thickness, the prediction accuracy of body density may be more influenced by visceral fat levels among the "non-obese but high levels of visceral fat" individuals. In addition, there is less influence of visceral fat levels on the prediction accuracy of body density in Japanese adults in the method using the suprailiac and abdominal skinfolds than the method using the triceps and subscapular skinfolds.

There are sex and age related differences in body fat distribution in Japanese adults. In males, body fat tends to accumulate at the abdomen, and this trend increases with age. In females, although body fat accumulation is found in the hips or lower limbs in younger women, abdominal fat accumulation tends to increase in postmenopausal women (Zamboni et al. 1992). Furthermore, Nagamine and Suzuki (1964) reported the triceps and subscapular skinfolds as useful sites for the prediction of body density for young Japanese adults. However, in this study with wide-ranging ages and obesity levels, suprailiac and abdominal skinfolds were more appropriate sites for prediction of body density in Japanese adults, compared with the triceps and subscapular skinfolds. This result may be caused by the differences in the age of subjects or agerelated characteristics of body fat distribution in Japanese adults. Eston et al. (2005) reported that skinfolds in the thigh and calf can explain most of the variance of whole body fat in young men and women. Thus, the contribution of skinfolds to whole body composition may change with age. Considering the characteristics of body fat distribution and its changes with age in Japanese adults, suprailiac and abdominal skinfolds may more accurately reflect their body density.

In summary, we measured subcutaneous fat thicknesses at 14 sites by ultrasound and skinfold caliper in Japanese adults with wide-ranging obesity levels, and we determined the characteristics of the measurement error in skinfold thickness at each site and the relationship with body density. Although measurement error in skinfold thickness tends to become greater with increasing obesity level, the influence of the increase in subcutaneous fat thickness on the measurement error was smaller at the abdominal and suprailiac skinfolds as compared with other sites. Suprailiac and abdominal skinfolds could accurately estimate body density, compared with the existing method, and our method showed no systematic error in the predicted value of body density.

\section{References}

Brozek, J., Grande, F., Anderson, J.T. \& Keys, A. (1963) Densitometric analysis of body composition: revision of some quantitative assumption. Ann. NY. Acad. Sci., 110, 113-140.

Demura, S., Kobayashi, H., Tanaka, K., Sato, S., Nagasawa, Y. \& Murase, T. (1999) Comprehensive evaluation of selected methods for assessing human body composition. Appl. Human Sci., 18, 43-51.

Eston, R., Evans, R. \& Fu, F. (1994) Estimation of body composition in Chinese and British men by ultrasonographic assessment of segmental adipose tissue volume. Br. J. Sports Med., 28, 9-13.

Eston, R.G., Rowlands, A.V., Charlesworth, S., Davies, A. \& Hoppitt, T. (2005) Prediction of DXA-determined whole body fat from skinfolds: importance of including skinfolds 
from the thigh and calf in young, healthy men and women. Eur. J. Clin. Nutr., 59, 695-702.

Forbes, G.B., Brown, M.R. \& Griffiths, H.J.L. (1988) Arm muscle plus bone area: anthropometry and CAT scan compared. Am. J. Clin. Nutr., 47, 929-931.

Garcia, A.L., Wagner, K., Hothorn, T., Koebnick, C., Zunft, H.J. \& Trippo, U. (2005) Improved prediction of body fat by measuring skinfold thickness, circumferences, and bone breadths. Obes. Res., 13, 626-634.

Komiya, S., Muraoka, Y., Zhang, F.S. \& Masuda, T. (1992) Age-related changes in body fat distribution in middle-aged and elderly Japanese. Journal of the Anthropological Society of Nippon, 100, 161-169.

Komiya, S., Eto, C., Otoki, K., Teramoto, K., Shimizu, F. \& Shimamoto, H. (2002) Gender differences in body fat of low- and high-body-mass children: relationship with body mass index. Eur. J. Appl. Physiol., 82, 16-23.

Nagamine, S. \& Suzuki, S. (1964) Anthropometry and body composition of Japanese young men and women. Hum. Biol., 36, 8-15.

Nakadomo, F., Tanaka, K., Hazama, T. \& Maeda, K. (1990)
Validation of body composition assessed by bioelectrical impedance analysis. Jpn. J. Appl. Physiol., 20, 321-330.

Tanaka, K., Nakadomo, F., Watanabe, K., Inagaki, A., Kim, H.K. \& Matsuura, Y. (1992) Body composition prediction equations based on bioelectrical impedance and anthropometric variables for Japanese obese women. Am. J. Hum. Biol., 4, 739-745.

The Examination Committee of Criteria for Obesity Diseasec in Japan, Japan Society for Study of Obesity (2002) New Criteria for "Obesity Disease" in Japan. Circ. J., 66, 987-992.

Weits, T., van der Beek, E.J. \& Wedel, M. (1986) Comparison of ultrasound and skinfold caliper measurement of subcutaneous fat tissue. Int. J. Obes., 10, 161-168.

Zamboni, M., Armellini, F., Milani, M.P., De Marchi, M., Todesco, T., Robbi, R., Bergamo-Andreis, I.A. \& Bosello, O. (1992) Body fat distribution in pre- and post-menopausal women: metabolic and anthropometric variables and their inter-relationships. Int. J. Obes. Relat. Metab. Disord., 16, 495-504. 